\title{
A Phenomenographic Study on University English Teachers' Perceptions of Online Classes during the COVID-19 Pandemic: A Focus on Iran
}

\author{
Zeinab Azizi ii \\ Department of Teaching English and Linguistics, Ayatollah Burojerdi University, Borujerd, Iran \\ Correspondence should be addressed to Zeinab Azizi; zeinab.azizi@abru.ac.ir
}

Received 18 December 2021; Accepted 28 January 2022; Published 21 February 2022

Academic Editor: Ayoub Bahnasse

Copyright ( $) 2022$ Zeinab Azizi. This is an open access article distributed under the Creative Commons Attribution License, which permits unrestricted use, distribution, and reproduction in any medium, provided the original work is properly cited.

\begin{abstract}
With the abrupt emergence and dissemination of the COVID-19 pandemic, all dimensions of life have been immensely affected across the globe. Concerning education, face-to-face classes have been replaced by online classes. This quick transformation may have brought about both advantages and disadvantages for education stakeholders and, accordingly, call for empirical studies to shed light on them. Hence, the present study aimed at demonstrating the advantages and disadvantages of online classes from the Iranian university English teachers' $(n=16)$ perceptions. To this aim, a phenomenographic approach was used to analyze the participants' perceptions gained through a reflective written statement. Findings yielded five advantages, including flexibility, selfdirectiveness, cost-effectiveness, improvement of professional competence, and increased motivation, as well as four disadvantages, namely, additional workload, technical and institution barriers, absence of face-to-face interactions, and student dishonesty. Finally, the study ends with proposing some implications for different stakeholders.
\end{abstract}

\section{Introduction}

It is deemed that hundreds of millions of users are using modern social technologies. A large part of this popularity lies in the fact that modern social technologies are available for free, engaging, and fun to use $[1,2]$. Concerning education, they have some notable advantages, such as ease of use, high functionality, great flexibility, and ubiquitous access [3-6]. These unique benefits have created massive interest in online classes (OCs).

Unlimited resources for learning and research are available to use with less constraint of time and location thanks to the new social technologies such as the Internet $[7,8]$. As Fry [9] notes, OCs include using the Internet and other new technologies to generate and present diverse course materials to students in any location away from instructors. Although there has not been a consensus over the definition of online learning, as the bedrock of OCs, it can be defined as "the use of new multimedia technologies and the Internet to increase learning quality by easing access to facilities and services as well as distant exchanges and collaboration" ([10], p. 12). In simple terms, online learning is the use of the new social media technologies to provide opportunities for different group ages to most benefit from online educational resources.

OCs have both potentials and challenges for higher education systems. For example, Wasilik and Bolliger [11] found out that "improved student access, increased rates of degree completion, and appeal of online education to nontraditional students" (p. 173) are the most noticeable advantages of OCs for higher education contexts. However, additional workload [12], technical and institutional barriers [13], and lack of face-to-face interactions $[14,15]$ are some of the disadvantages of OCs.

In March 2019, an event drew education stakeholders' attention to OCs. This event was the COVID-19 pandemic. This pandemic has created dramatic changes in all dimensions of life. Countries have tried to decrease the presence of people outside due to health problems. Incompatible with this condition, all education systems at different levels have 
either postponed or canceled out all education activities or transferred them to OCs [16]. In Iran, the tertiary level tried to adapt itself to the current situation and moved most educational activities to OCs. This unique condition needs to explore the advantages and disadvantages of OCs in the Iran higher education contexts. For this purpose, the present study aims at disclosing the potentials and challenges of OCs from university teachers' perceptions. The hope is that the findings can be useful for different educational stakeholders to improve the quality of OCs in the Iranian higher education centers.

\section{Literature Review}

2.1. Theoretical Foundations. The theoretical underpinnings of OCs are ascribed to the social constructivism theory $[17,18]$, the theory of learning for the mobile age [19], and the motivation learning theory [20]. The underlying assumption of the social constructivism theory is that real learning happens in a communicative context in which students interact with others to construct the required knowledge and skills to do a task or solve a problem $[17,18]$. The connection of this theory to OCs, as Parsons et al. [21] note, is that OCs would be highly useful to hone instructors' professional development and, accordingly, their job performance if they have enough social educative engagement with other colleagues and students, as well as if they can adapt it with their learners' needs and wants in a specific context. From this perspective, it is argued that by being an expert at using modern social media technologies, university teachers can gain a range of opportunities to have social interactions with other educational centers, well-experienced teacher educators, and qualified colleagues across the country or even the globe to improve or modify their professional competence. The present situation, in turn, can positively affect their performance in OCs.

In congruence with the social constructivism theory, the theory of learning for the mobile age [19] assumes that modern social technologies have made knowledge and information more available with fewer constraints of time and location. According to this theory, university teachers and students "now have the opportunity to access knowledge ondemand across time and space, moving within and through content and revisiting it as needed" ([21], p. 35). From this perspective, university teachers and students have more control over their teaching and learning. The ways and content of teaching and learning are not restricted by one person or institution. Also, the mobile age has removed this undeniable limitation that learning can just occur in official spaces such as classroom contexts. It has let learning occur in long, extended sessions or in brief chunks of time. Finally, as Simpson et al. [22] put it, due to the interactive nature of mobile learning, university teachers and students can connect with others and create a network of ideas, which is beneficial to construct the required knowledge and skills.

The third theory, namely, motivation, can also support the use of OCs. Under the lens of expectancy-value theory, it is argued that motivation is conceptualized in terms of two concepts: expectancy and value [23]. The former refers to a university teacher's expectation of success in his/her career duties. The common question for this concept is as follows: can I succeed in online teaching? The latter deals with the values that a university teacher puts into doing a teaching task. The common question for this concept is as follows: do I want to do the online teaching? When university teachers have positive expectations of success in online teaching and are confident that they can do it well, their motivation will dramatically increase [21]. This increased motivation pushes the university teachers to put more time and effort into their careers and, consequently, achieve more promising results.

2.2. Advantages of OCs. In the literature past, some advantages to OCs have been listed. One of the most-cited benefits is flexibility $[14,24,25]$. This advantage refers to the fact that the teachers and students who cannot join face-toface classes can attend OCs easily. Additionally, according to Smedley [26], in OCs, university teachers have more considerable flexibility to design their syllabus based on their conditions. The other advantage of OCs is self-directiveness. This benefit deals with the view that university teachers can complete the course at a higher speed without any pressure, or they can start the next course sooner if the requirements of the current course have been met [11]. Also, OCs make teachers more self-regulated in the sense that they can design, implement, and evaluate courses based on their own potentials and limitations. Being cost-effective is another equally important benefit of OCs [27]. Both universities and teachers can save much time and money due to deleting costs related to providing suitable classes, sports facilities, library facilities, and the like [28].

The other noticeable profit of OCs is improving teachers' professional competence [29]. It is argued that during working in OCs, teachers are implicitly encouraged to learn new knowledge and skills. They are pushed to adapt and, even, modify their old ways of teaching with newly designed technologies. Accordingly, it is supposed that their professional competence is to hone [11]. The last advantage of OCs is that they are interesting for teachers. As Panda and Mishra [30] note, working with new modern social technologies is absorbing for individuals. They dig in the new world, encounter new things, find their favorite things, and satisfy their needs. All these unique features have led to increased motivation among its users [11].

2.3. Disadvantages of OCs. If there are advantages with OCs, undoubtedly, there are disadvantages. The most considerable disadvantage of OCs vis-à-vis traditional classes is the additional workload [31]. As the previous research works evidenced [25, 32-34], preparing and presenting highquality materials require more time, effort, and energy on the part of teachers. In this regard, it is assumed that online teaching is more than merely presenting a couple of sides in front of the class [35-37]. Another drawback of OCs is technical and institutional problems. It means that since newly designed apps and platforms bring new options, it makes it very hard for teachers to know how to use them easily [11]. If the required facilities are not provided by 
education centers or they are not trained well on how to use them effectively, teachers face lots of $[35,36,38]$.

The absence of face-to-face interactions is another demerit $[14,39]$. In this regard, when there are no face-to-face interactions between teachers and students, it may be hard to detect the points when students need their teacher's help and scaffolding. Coupled with this, as Wasilik and Bolliger [11] note, the lack of face-to-face interactions in OCs may deprive students of pair or group works where they can learn from one another. Last but not least, student dishonesty is another drawback of OCs. In this respect, teachers may find it hard to trust their students concerning the course assignments and projects and written tests that are got to be completed and done by the students themselves [40].

2.4. Related Studies in the Literature. Here, we critically review some of the previous studies to lay the groundwork for the current study. In the research by Hislop and Ellis [25], an attempt was made to clarify if online teaching is more time-consuming and demanding vis-à-vis traditional instruction. They found that the time spent on the online teaching sections was less compared to the traditional instruction of the same sections. However, the findings disclosed that the effort expended on the online teaching OCs was higher than the traditional instruction.

In another research work, Kim et al. [14] probed into the experiences of university students who have been attending online courses over two semesters. Their findings revealed that flexibility, efficiency, and increased group work were the key advantages of online learning. However, their results evidenced that the absence of face-to-face interactions was the biggest disadvantage of OCs. In another study by Wasilik and Bolliger [11], the faculty members' satisfaction with OCs in the USA was investigated. In general, their results evidenced that the participants were moderately satisfied with OCs. Additionally, their findings indicated that a large part of the participants' satisfaction was associated with flexibility, accessibility, diverse student population, high levels of student participation and motivation, student interaction, depth of student responses, class management, permanent communication transcripts, professional development opportunities, enjoyment of working with technology, and support by colleagues.

Further, the findings revealed that the main frustrations related to OCs were technological difficulties, lack of face-toface contact, and student involvement. Moreover, Ohanu and Chukwuone [38] examined why Nigerian Technical Education (TE) instructors are reluctant to use newly developed online platforms. The findings evidenced that technical and institutional barriers were discouraging the participants to use the online platforms. Finally, Abushammala [41] investigated the university perceptions of the effects of OCs during the COVID-19 pandemic on their studies in Omen. The findings revealed that the participants were not satisfied with OCs due to the additional assignments and extra tuitions.

In the Iranian context, Ghashghagh et al. [42] attempted to identify the influencing factors in creating a positive attitude toward the use of OCs. Their results evidenced that the resistance to change had the greatest effect and negative attitude toward OCs has the least influence on using OCs. Finally, Zamani et al. [43] examined the factors that inhibited the use of OCs among faculty members of universities. Their findings disclosed that the contextual factors have the most adverse effect on using OCs in the Iranian higher contexts.

\section{Context of the Study}

With the abrupt emergence and development of the COVID-19 pandemic in March 2019, all dimensions of life have been immensely affected across the world [44]. Along with substantial health problems, the global economy and business have been adversely affected. The education systems of all countries faced a new situation in which most classes at elementary, secondary, and tertiary levels were transferred to the virtual space $[41,45,46]$. This phenomenon has created both challenges and potentials for different educational stakeholders. For example, in the Iranian context, the ministry of education started to teach the school materials on the national TV channels and designed and produced a new app named Shad to assist school teachers to run their classes online. At universities, the officials tried their best to provide the required facilities for running OCs. Most universities set up Adobe Connect Platform and a learning management system (LMS) through which both university teachers and students can attend OCs. In addition, the university students were asked to make WhatsApp groups be in touch with their university professors and classmates. Using both LMS and WhatsApp, the university teachers have been doing their best to provide a setting in which the required course materials to be presented as efficiently as possible to their students. Without a doubt, these OCs might have brought out both advantages and disadvantages which need to be verified in detail. To do so, the present study purported to disclose the advantages and disadvantages of OCs during the COVID-19 pandemic from Iranian university teachers' perspectives. It is hoped that the study's findings can be illuminative for different higher education stakeholders. To meet this objective, the following research question was put forward:

What are Iranian university English teachers' perceptions of online classes during the COVID-19 pandemic?

\section{Method}

4.1. Research Design. To run the present study, a phenomenographic design was used. As Richardson [47] notes, a phenomenographic approach is used to disclose the perceptions of a group of people about a particular phenomenon. The results yield some concepts and factors disclosing the different ways through which an event is conceptualized by a group of people. The extracted conceptions are used to "expand what we know about the psyche of different people" ([48], p. 12). Hence, a phenomenographic approach was used to uncover Iranian university English teachers' 
perceptions of the advantages and disadvantages of OCs during the COVID-19 pandemic.

4.2. Participants. The study's sample included sixteen university teachers at Ayatollah Borujerdi University and Lorestan University in Lorestan Province, Iran. The demographic information of the participants is presented in Table 1. The participants were selected using purposeful sampling. According to Miles and Huberman [49], it is the most frequent sampling method in the qualitative paradigm to identify and choose the intended case of the information. Different factors such as gender, teaching experience, major, and academic rank were considered to meet heterogeneity and maximum variation criteria [50]. To achieve the participants, the researcher referred to the Deputy of Education of the universities and explained the objectives of the present study. They allowed the researchers to run the study at the universities. Then, the names, majors, and telephone numbers of the university teachers were taken. Next, the first researcher contacted the university teachers, explained the study's objectives, and asked if they would be willing to participate in the study. For those who were ready to participate, a reflective written statement was sent via e-mail or WhatsApp.

4.3. Ethical Considerations. The researchers tried to satisfy the ethical requirements during the formulation and completion of the present study. To this aim, proper ethics approval was received from the university officials. Besides, digital written consent (in Persian) was signed and returned to the researchers by the participants. The participants became aware of what their participation was required. They were said that the participation is voluntary and they can withdraw the study as they wished. They were ensured that their names and responses would remain confidential and they would be informed about the final results.

4.4. Instruments and Data Collection Procedures. The required data were collected through a reflective written statement. They were invited to write about their perceptions and experiences of OCs during the COVID-19 pandemic. Given the fact that the university settings are the same for the participants across the province, the statements of the participants were merged to assure the credibility of the given claims based on the data. The participants were invited to write about the following prompt in detail:

Dear professor.

As you know, with the emergence and dissemination of the COVID-19 pandemic, the universities and higher education centers have been closed and most classes have been held online. This event might have brought about advantages and disadvantages for different higher education stakeholders. Hence, the present study aims at exploring the advantages and disadvantages of OCs from your perceptions. We would appreciate your time to answer the following questions and send back the responses to us soon:
TABLE 1: Demographic information of the participants.

\begin{tabular}{|c|c|c|c|c|}
\hline Participant & Gender & Level & Major & Teaching experience \\
\hline Behzad & Male & $\begin{array}{l}\text { Ass } \\
\text { Prof. }\end{array}$ & $\begin{array}{c}\text { Applied } \\
\text { linguistics }\end{array}$ & 8 \\
\hline Omid & Male & $\begin{array}{l}\text { Ass } \\
\text { Prof. }\end{array}$ & $\begin{array}{c}\text { Applied } \\
\text { linguistics }\end{array}$ & 12 \\
\hline Nader & Male & $\begin{array}{l}\text { Ass } \\
\text { Prof. }\end{array}$ & Linguistics & 7 \\
\hline Zohreh & Female & $\begin{array}{l}\text { Ass } \\
\text { Prof. }\end{array}$ & $\begin{array}{c}\text { Applied } \\
\text { linguistics }\end{array}$ & 8 \\
\hline Shahram & Male & $\begin{array}{l}\text { Ass } \\
\text { Prof. }\end{array}$ & $\begin{array}{l}\text { English } \\
\text { literature }\end{array}$ & 27 \\
\hline Arman & Male & $\begin{array}{l}\text { Ass } \\
\text { Prof. }\end{array}$ & Linguistics & 12 \\
\hline Ayoob & Male & $\begin{array}{l}\text { Ass } \\
\text { Prof. }\end{array}$ & $\begin{array}{c}\text { Applied } \\
\text { linguistics }\end{array}$ & 8 \\
\hline Mohammad & Male & $\begin{array}{l}\text { Ass } \\
\text { Prof. }\end{array}$ & $\begin{array}{l}\text { English } \\
\text { literature }\end{array}$ & 10 \\
\hline Parviz & Male & $\begin{array}{l}\text { Ass } \\
\text { Prof. }\end{array}$ & $\begin{array}{l}\text { Applied } \\
\text { linguistics }\end{array}$ & 9 \\
\hline Mahdieh & Female & $\begin{array}{l}\text { Ass } \\
\text { Prof. }\end{array}$ & Linguistics & 5 \\
\hline Marjan & Female & $\begin{array}{l}\text { Ass } \\
\text { Prof. }\end{array}$ & $\begin{array}{l}\text { English } \\
\text { literature }\end{array}$ & 7 \\
\hline Mahmood & Male & $\begin{array}{l}\text { Ass } \\
\text { Prof. }\end{array}$ & Linguistics & 15 \\
\hline Zahed & Male & $\begin{array}{l}\text { Ass } \\
\text { Prof. }\end{array}$ & $\begin{array}{c}\text { Applied } \\
\text { linguistics }\end{array}$ & 10 \\
\hline Majid & Male & $\begin{array}{l}\text { Ass } \\
\text { Prof. }\end{array}$ & $\begin{array}{c}\text { Applied } \\
\text { linguistics }\end{array}$ & 4 \\
\hline Leila & Female & $\begin{array}{l}\text { Ass } \\
\text { Prof. }\end{array}$ & Linguistics & 6 \\
\hline Ehsan & Male & $\begin{array}{c}\text { Ass } \\
\text { Prof. }\end{array}$ & $\begin{array}{c}\text { English } \\
\text { literature }\end{array}$ & 13 \\
\hline
\end{tabular}

(1) From your perspective, what are the most significant advantages of online classes?

(2) From your perspective what are the biggest disadvantages of online classes?

(3) How would you describe your own experiences with online classes?

(4) What are your suggestions to improve online classes?

(5) Please write your major, gender, academic rank, and teaching experiences. This information would be only used to give the demographic information of you.

In a digital format, the written reflective statements reflecting the university teachers' experiences with OCs were collected in a digital database. In order not to restrict the participants' perceptions, the researchers did not specify any factor or concept beforehand. Instead, the university teachers were encouraged to address the questions from their perspectives and freely write about their perceptions and experiences in their mother tongue (Persian). Finally, it should be noted that the researcher recruited two well-experienced translators to translate the participants' responses into English. 
4.5. Data Analysis Procedures. In congruence with the basic tenets of the phenomenographic approach, the university teachers' words and perceptions were analyzed through a criterion of proximity [51]. The data analysis consisted of six distinct stages which are detailed below.

Stage 1: identifying the statements of the participants which were highly relevant to their perceptions of the advantages and disadvantages of OCs.

Stage 2: conjugating and organizing the selected words and expressions to construct the initial themes. In doing so, Sjöström and Dahlgren's [52] principles, including frequency, status, and pregnancy were used.

Stage 3: arranging the prethemes in brunches to keep the participants' perceptions in a tree of meanings.

Stage 4: selecting the excerpts that highly represented the prethemes generated in the precedent stages. In this stage, the researchers did their best not to change the intended meanings of the participants' words.

Stage 5: comparing and contrasting each of the extracted excerpts with the other ones to create a pool of meanings. As Harris [53] stresses, this helped the researchers to give correct meanings to the excerpts and assign an appropriate connotation during the comparison and contrast.

Stage 6: determining the final themes and the most representative excerpts for them.

It should be noted that the researchers recruited two experts in qualitative research to measure the consistency of the findings. They examined the themes and excerpts independently and their interrater reliability was $(0.89)$ which was considered acceptable for the current study's purposes. Also, the credibility of the results was ensured through a member checking strategy. In doing so, the researchers gave a copy of the final findings to four participants to check out if they represented their intended meanings. In general, they confirmed that the extracted themes and excerpts matched their intended meanings.

\section{Findings and Discussion}

In this part, the inductively generated themes are presented along with the supporting findings. Then, the results are discussed in light of the literature (see Figure 1).

\subsection{Advantages of $\mathrm{OCs}$}

5.1.1. Flexibility. One of the recurring themes that gained considerable attention from the participants was flexibility. In support of this, one of the participants quoted:

(1) In online courses, there is a fair amount of flexibility. I mean that I can change the course materials and the number of sessions based on the contextual conditions. For example, if my students need more explanations, I can make up more sessions without any limitations. (Ehsan, May 24, 2020)
In corroborating with the precedent statement, one of the university teachers commented:

(2) Online courses are really advantageous. If some of my students cannot attend the class because of being employed, sick, or away from the university, they can use the recorded clip taken from the class. As such, in every session, I do not need to review the previous materials again. (Leila, May 17, 2020)

The findings above indicated that one of the most significant advantages of OCs is flexibility. Along with Davis et al. [24], the study's results can be explained from this view that OCs are highly beneficial for those university students who cannot attend face-to-face classes owing to having parttime or full-time jobs or being distant from the institutions. Additionally, the study's findings are in line with those of Hemsley [54] which showed that the flexibility of OCs lies in this reality that students can keep pace with their path to graduation even if they have temporary conflicts such as health issues and they cannot physically be present on the campus [14]. Further, the study's findings lend support to Smedley [26], who notes that to university instructors, OCs can be found beneficial because they can create a kind of flexibility in their syllabus. In this regard, they can adapt the course materials based on their existing conditions. Likewise, the study's results show support to those of Hislop and Ellis [25], reporting OCs are flexible since the university teachers can be sure that their classes will not be canceled due to bad weather, a trip, and traffic jams. In sum, according to Smedley [26], OCs provide both learners and instructors plenty of time and place choice rights.

5.1.2. Self-Directiveness. The other theme extracted from the data was self-directiveness. In this regard, one of the participants commented:

(3) Since the online courses have been started with the emergence of COVID-19, I have got more independent in doing my teaching duties. I mean, with the absence of university officials, I am planning and doing my career duties for myself. (Majid, May 17, 2020)

Following the previous statement, another participant opined that her students have got more selfdirected learners. In this respect, quoted:

(4) Online courses have made my students more selfdirected. I mean that my students are taking more responsibilities in the process of their learning. They are seeking more information on the Internet, joining more online groups and forums, and benefiting from online course materials. (Zahed, May 18,2020$)$

As the above statements disclosed, another important advantage of OCs is self-directiveness. In alignment with Yot-Domínguez and Marcelo [55] and Davis et al. [24], the findings may be explained from this view that OCs made university teachers more self-directed and, consequently, motivated them to be more successful in doing 


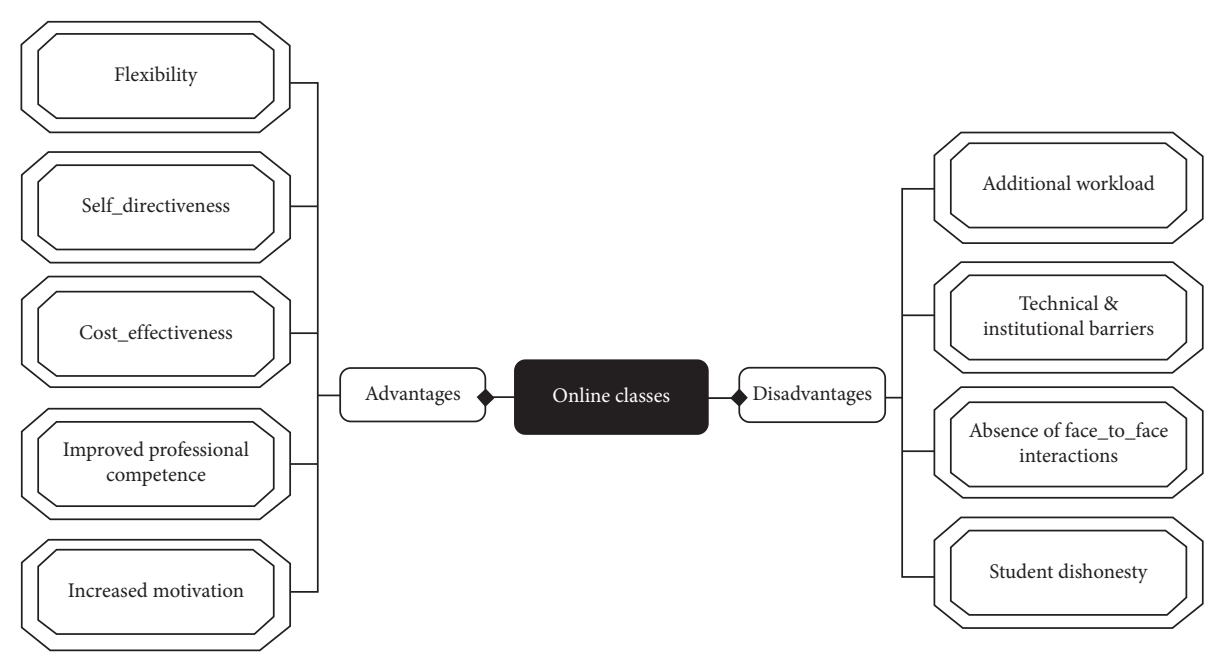

Figure 1: A model of advantages and disadvantages of OCs.

their career duties The findings, indeed, evidenced that during OCs, the university teachers got more disciplined and did their job duties without any pressure on the part of university officials. Also, along with Wasilik and Bolliger [11], the study's findings are explained from this perspective that the university teachers felt the sense of self-directiveness as OCs offered opportunities for them to complete the course with an advanced speed before its deadline, or they could start the next responsibility or new course sooner. It means that due to OCs, the university teachers and students could teach or learn at their own pace and they were pushed to plan, implement, and evaluate their teaching and learning tasks tailored to their conditions. This, in turn, might make the university teachers and students more self-regulated and independent. The study's findings, finally, accord with those of Ice et al. [56], reporting that OCs made their participants rely on themselves because teachers were no longer the sole source of information and knowledge.

5.1.3. Cost-Effectiveness. Another theme that came out of the data was "cost-effectiveness." In this regard, one of the participants asserted:

(5) Opposed to the traditional courses, many costs are eliminated in online classes. For example, university teachers and students are not obliged to spend any time and money commuting to the university. (Zohreh, May 18, 2020)

In congruence with the precedent statement, another university teacher confirmed this point and commented:

(6) With the emergence and spread of COVID-19 and the development of online classes, many costs have been reduced in favor of our university. For example, the cost of providing suitable classes, library, laboratory, sports facilities, dormitory facilities, and meal facilities has been completely deleted. (Mohammad, May 18, 2020)
As the statements above showed, cost-effectiveness is an important benefit of OCs. Along with Limperos et al. [27], the study's findings can be justified from this respect that OCs are cost-effective for university teachers and students in terms of time and money. They do not have to spend any time and money to commute to their classes or pay fees to rent a dormitory nearby the campus. In addition, the study's results, in line with Luyt [57] clarified that OCs have been highly cost-effective to the institution owners and education officials since they do not have to provide classes and buildings, as well as they are capable of offering lots of classes with the maximum number of learners. Besides, as Algahtani [28] stresses, the study's findings are indicative that because there is no limit with the virtual space compared to the physical space of the campus, university teachers can also make up their classes on their own and their students' convenience. All these can lead to saving time, money, and energy for the different stakeholders.

5.1.4. Improvement of Professional Competence. Another theme catching the attention of the participants' was "improvement of professional competence." In support of this, one of the respondents remarked the following:

(7) To be successful in online courses, I have to use different apps and platforms with their unique facilities, such as tape recorder, projector, slide, overhead, and the like. Plus, I need to prepare and present the course materials differently from the traditional classes. This, accordingly, makes me learn new ways of teaching. (Nader, May 20, 2020)

Another participant affirmed the previous statement and asserted that his digital literacy significantly improved with OCs. He stated:

(8) Before the online classes, I did not know too much about digital technologies. Now I can use and benefit from the modern social technologies in my academic and daily life as well as doing research via new paths. (Shahram, May 22, 2020) 
These words documented that another noticeable profit of OCs is providing valuable opportunities for the university teachers to promote personally and professionally. As Betts [29] highlights, the reason for the findings may lie in the fact that the university teachers might be encouraged to learn new knowledge and skills about OCs and become more familiar with newly developed technologies and novel instructional methods and techniques. This, in turn, may result in the development of their digital literacy. An equally significant reason for the study's results is that OCs might encourage the university teachers to find new ways in the preparation and presentation of their course materials that, accordingly, could hone their professional competence $[30,58]$. Plus, in congruence with the study's findings, as Thompson [59] points out, OCs offered additional opportunities for the university teachers to do more research in new directions and have interdisciplinary cooperation with other colleagues.

5.1.5. Increased Motivation. The last recurring theme was "increased motivation." On the side of this theme, one of the university teachers remarked:

(9) Working with modern technologies is so absorbing for me. I mean, since I have enough time to do my teaching career with an amount of flexibility and I can manage my own time well, it is really exciting to me. (Omid, May 23, 2020)

In corroborating with the precedent comment, another respondent stated:

(10) I think that my self-gratification is increasing since OCs are more intellectual and interesting to me. Additionally, working with OCs makes me motivated as I can meet my career expectations. (Behzad, May 20, 2020)

As the above quotations uncovered, the last advantage of OCs is increasing university teachers' motivation. The study's findings can be explained from the motivation theory [23]. As the university teachers could meet their career expectations and find their job valuable in OCs, they got motivated to work more with the OCs. Additionally, along with Hamid et al. [1], the very reason for the study's findings is that OCs might be appealing for the university teachers since they could work at their own expedited pace through materials, complete a course without the undue pressure that existed with the face-to-face classes, and open up time in their schedule for other career and life duties. Moreover, the study's results are in line with those of the previous studies [11,30,60-62], which demonstrated that OCs are motiving for the university teachers as they result in increased self-gratification, offer more intellectual challenges, and lead to an increased interest in using new technologies.

\subsection{Disadvantages of OCs}

5.2.1. Additional Workload. The first recurring theme as a disadvantage of OCs was "additional workload." In support of this, one of the participants stated:
(11) Compared to traditional classes, online classes require more time and effort. You know, the way of teaching in online classes is different. I need to spend more time and effort preparing and presenting the course materials and keep myself updated with the new technologies (Mahdieh, May 21, 2020)

Corroborating with the previous statement, another university teacher commented:

(12) In online courses, the students expect that I be available 24/7. Also, I do not have any noticeable influence on the students' behavior. I think that my role has diminished as a materials presenter. (Ayoob, May 18, 2020)

The statements above indicated that the most noticeable disadvantage of OCs is imposing an additional workload on university teachers compared to face-to-face classes [31]. As the findings documented, the reason is that in OCs, university teachers have to put more thought, time, and energy into the preparation and presentation of the course materials $[25,32-34]$. In line with the study's findings, it may be argued that effective online teaching requires more than just merely posting and presenting lectures via slides. In alignment with Young [12], another equally important reason for the study is associated with the unrealistic expectations of students who expect that their university teachers should be available 24 hours a day, seven days a week basis. Another possible reason for the additional workload in OCs, as Arbaugh [35] notes, is that university teachers find it really demanding to keep themselves dated with cutting-edge technology. The study's findings are in congruence with those of Hung and Chou [36] and Schoonenboom [37], reporting that their participants complained that their traditional role as a direct controller of the teaching process in the face-to-face classes has shifted into a facilitator in OCs.

5.2.2. Technical and Institutional Barriers. Another frequent theme extracted from the data was "technical and institutional barriers." In this respect, one of the respondents expressed disdain with OCs:

(13) In the ever-changing world of modern social technologies, I need to keep myself updated. When using a new app or platform in my classes, I encounter some new technical problems, and I do not know how to handle them on the spot. Hence, they adversely affect my teaching. (Majid, May 17, 2020)

Another university teacher complained about the lack of required facilities to run OCs at her university. In this respect, he quoted:

(14) With the dissemination of COVID-19, we had to hold our classes online. But, unfortunately, the facilities of our university were not enough to do so. For example, the Internet access and speed are really poor. Also, our classes are usually stopped due to the problems with LMS in the university's servers. (Mahdieh, May 20, 2020) 
These words unveiled that another limitation in OCs is technical and institutional barriers. Based on the study's findings, it can be argued that university teachers may prefer to work in face-to-face classes because, in OCs, they need to keep themselves updated with the ever-growing technological advancements $[35,36]$. It is easy to imagine that when university teachers do not know much about a newly designed platform or application, they may encounter different technical problems while using it in their classes. Furthermore, in alignment with Schoonenboom [37], the study's results evidenced that if universities do not provide the appropriate online platforms and apps and do not train their instructors as to how to use them, it is expected that OCs cannot meet the educational objectives. In this regard, the study's findings lend support to Gamdi and Samarji [13], who consider poor Internet access as one of the common barriers in OCs. Also, the study's results show support to those of Zamani et al. [43], reporting that the absence of required support from universities was the major obstacle in the use of online teaching by Iranian faculty members. Likewise, the study's findings are in congruence with Sedghpor and Mirzaee's [63] results. They documented that faculty members were reluctant to utilize OCs due to their unfamiliarity with superior knowledge and skills that are essential to perform well in this new environment.

5.2.3. Absence of Face-to-Face Interactions. The next theme that emerged from the participants' responses was the "absence of face-to-face interactions" in OCs. One of the participants complained:

(15) A significant limitation of OCs is that I do not have face-to-face interactions with my students. When I cannot see my students' faces, I cannot see if they are engaged in the lesson processes and if my teaching is tailored to their needs and wants. (Parviz, May 16, 2020)

Further, another university teacher wrote that the lack of face-to-face interactions in OCs does not let the university students take advantage of their peers' help and collaboration. He commented:

(16) Well, in online classes, the students have less interaction with their peers, and I cannot use pair or group work activities. (Ehsan, May 24, 2020)

As these statements clearly show, another disadvantage of OCs is the absence of face-to-face interactions with students and group interactions. Along with Davis et al. [24], the study's results disclosed that the absence of face-to-face interactions with students in OCs may make the university feel that their students were not actively involved in the class. Therefore, to compensate this, they may try to put more effort into engaging the students by calling them. Moreover, the study's findings, as Wasilik and Bolliger [11] found, documented that university students may feel isolated from other students because of the deprivation of their peers' help and cooperation. Likewise, the study's results indicated that the lack of face-to-face interactions has made it difficult for university teachers to know the appropriate time to provide the proper feedback and scaffolding when students are struggling. As opposed to traditional face-to-face classes, in line with the results, it is very challenging to understand if a university student needs more support and feedback owing to the absence of clues like tardiness and body language in OCs [64]. Finally, the study's findings lend credence to those of Zamani et al. [43], revealing that their participants expressed disdain with OCs, owing to a lack of face-to-face interactions. They reasoned that in OCs, teachers and students use mental construction of knowledge and written messages to interact with each other something that is not very pleasing for them.

5.2.4. Student Dishonesty. The last theme extracted from the collection was "student dishonesty." In this regard, one of the participants opined:

(17) As I give an assignment to my students, I do not know if they are the students themselves who do it or another person. I fear that my students do not pay enough attention to their course assignments because they know that there is another person or source that can do the job for them, and they can pass the course easily. (Zahed, May 18, 2020)

Corroborating with the previous participant, another university teacher blame for this issue and stated:

(18) Sometimes, my students' responses to my test items do not represent their real abilities. I feel that they answer the test items with the help of their course books and other sources. So, I cannot trust that they have fully learned the course materials. (Shahram, May 24, 2020)

As the statements evidenced, "student dishonesty" is another drawback of OCs. The study's findings can be explained from this reality that sometimes university teachers may find it hard to trust their students concerning the course assignments and projects, as well as the written tests got to be completed and done by the students themselves. Additionally, to explain these findings, it can be said that owing to diverse reasons, such as lack of time, being employed, being lazy, and having the desire to get a higher score or pass a course, some university students may pollute their scores by receiving an illegal hand from other sources [65]. The study's findings are in alignment with Wade and Peggy [66], arguing that this kind of distrust may create a negative view toward the use of OCs among university teachers.

\section{Conclusion and Implications}

The present study purported to further our understanding of the advantages and disadvantages of OCs from the Iranian university English teachers' perceptions during the COVID19 pandemic. The results yielded some advantages, including flexibility, self-directiveness, cost-effectiveness, improvement of professional competence, and increased motivation, as well as some disadvantages, namely, additional workload, 
technical and institutional barriers, absence of face-to-face interactions, and student dishonesty.

In line with the study's findings, a range of implications is offered. Firstly, education officials of universities need to take up urgent steps to remove all contextual obstacles in running OCs. For example, they can assign a particular budget on the required facilities to run OCs successfully. Secondly, the university officials may want to take urgent actions to hold up in-service training courses on new platforms and apps. In this way, it can be ensured that university teachers are equipped with the required knowledge and skills to run effectively their OCs. Thirdly, it is up to the university officials to offer extra compensations and rewards for the university teachers who are functioning well in OCs. For instance, work productivity in OCs can be an integral part of getting annual promotions. Fourthly, preservice teacher training courses need to incorporate digital literacy materials. In this sense, it can be assured that teachers become familiar with contemporary technologies and, accordingly, can benefit from them in their jobs. Fifthly, university teachers should adapt themselves to the modern world and develop their knowledge and skills of the newly designed online platforms and apps. In other words, as Bonk [63] rightly puts it, since students' expectations on the quality of OCs are overgrowing, university teachers should keep themselves updated so that they can satisfy their expectations and needs. Sixthly, under the premise that university teachers are no longer the solitary source of information and knowledge, university students should adapt themselves to OCs and try to rely on themselves. Finally, students may feel the stress of online learning because of loneliness and isolation from peers, increased workload, prolonged screen time, and less one-on-one instructional support. Parents can help them manage stress by listening to their challenges, encouraging frequent breaks, and offering support.

Some suggestions for further research in light of the limitations imposed on the current study are recommended. As the sample of the current study was limited to a small number of participants $(n=16)$ in two universities, further studies are needed to be carried out in other universities in Iran to increase the generalizability of the current study's findings. Moreover, since the selection of the participants was restricted to university teachers, further research works can also investigate university students' perceptions of the potentials and barriers in the use of OCs. Likewise, future studies may do the same study in state school and private language institute contexts, including different stakeholders, such as school principals, teachers, students, and parents. Further, as the findings indicated, the absence of face-to-face is a considerable limitation with OCs; therefore, future studies can seek new strategies and techniques to maximize the interactions and group works. Finally, as digital literacy is considered indispensable for university teachers in OCs, more studies are required to probe into the connection of digital literacy with university teacher's job performance and job satisfaction both quantitatively and qualitatively.

\section{Data Availability}

The data are available if the request will be found reasonable by the author.

\section{Conflicts of Interest}

The authors declare that they have no conflicts of interest.

\section{References}

[1] S. Hamid, J. Waycott, S. Kurnia, and S. Chang, "Understanding students' perceptions of the benefits of online social networking use for teaching and learning," The Internet and Higher Education, vol. 26, pp. 1-9, 2015.

[2] K. McShane, "Integrating face-to-face and online teaching: academics' role concept and teaching choices," Teaching in Higher Education, vol. 9, no. 1, pp. 3-16, 2004.

[3] S. Brown, "From VLEs to learning webs: the implications of web 2.0 for learning and teaching," Interactive Learning Environments, vol. 18, no. 1, pp. 1-10, 2010.

[4] R. A. Glazier, K. Hamann, P. H. Pollock, and B. M. Wilson, "What drives student success? Assessing the combined effect of transfer students and online courses," Teaching in Higher Education, vol. 26, no. 6, pp. 839-854, 2019.

[5] R. Jopp and J. Cohen, "Choose your own assessment-assessment choice for students in online higher education," Teaching in Higher Education, vol. 24, pp. 1-18, 2020.

[6] A. Schroeder, S. Minocha, and C. Schneider, "The strengths, weaknesses, opportunities and threats of using social software in higher and further education teaching and learning," Journal of Computer Assisted Learning, vol. 26, no. 3, pp. 159-174, 2010.

[7] N. Ahmed Abdullah and M. Sultana Mirza, "Evaluating preservice teaching practice for online and distance education students in Pakistan," International Review of Research in Open and Distance Learning, vol. 21, no. 2, pp. 81-97, 2020.

[8] R. Hartshorne and H. Ajjan, "Examining student decisions to adopt web 2.0 technologies: theory and empirical tests," Journal of Computing in Higher Education, vol. 21, no. 3, pp. 183-198, 2009.

[9] K. Fry, "E-learning markets and providers: some issues and prospects," Education + Training, vol. 43, no. 4-5, pp. 233-239, 2001.

[10] European Commission, The E-Learning Action Plan: Designing Tomorrow's Education, 2001, http://www.elearningeuropa.info.

[11] O. Wasilik and D. U. Bolliger, "Faculty satisfaction in the online environment: an institutional study," The Internet and Higher Education, vol. 12, no. 3-4, pp. 173-178, 2009.

[12] J. R. Young, The 24-Hour Professor: Online Teaching Redefines Faculty Members' Schedules, Duties, and Relationships with Students, Chronicle of Higher Education, Washington, DC, USA, 2002.

[13] M. A. A. Gamdi and A. Samarji, "Perceived barriers towards e-learning by technical education teachers at a recently established University in Saudi Arabia," International Journal of Information and Education Technology, vol. 6, no. 1, pp. 23-28, 2016.

[14] K. J. Kim, S. H. Liu, and C. J. Bonk, “Online MBA students' perceptions of online learning: benefits, challenges, and suggestions," The Internet and Higher Education, vol. 8, no. 4, pp. 335-344, 2005.

[15] K. Nuri, "Enablers and barriers of online learning during the COVID-19 pandemic: a case study of an online university 
course," Journal of University Teaching and Learning Practice, vol. 18, no. 4, 2021, https://ro.uow.edu.au/jutlp/vol18/iss4/11.

[16] S. Ramlo, "The coronavirus and higher education: faculty viewpoints about universities moving online during a worldwide pandemic," Innovtive Higher Education, vol. 46, pp. 241-259, 2021.

[17] J. Lave and E. Wenger, Situated Learning: Legitimate Peripheral Participation, Cambridge University Press, Cambridge, UK, 1991.

[18] L. S. Vygotsky, Mind in Society: The Development of Higher Psychological Processes, Harvard University Press, Cambridge, MA, USA, 1978.

[19] M. Sharples, J. Taylor, and G. Vavoula, "A theory of learning for the mobile age," in The SAGE Handbook of E-Learning Research, R. Andrews and C. Haythornthwaite, Eds., pp. 221-247, Sage, Thousand Oaks, CA, USA, 2007.

[20] A. Wigfield, S. M. Tonks, and S. L. Klauda, "Expectancy-value theory," in Handbook of Motivation at School, K. R. Wentezel and D. B. Miele, Eds., pp. 55-74, Routledge, London, UK, 2nd edition, 2016.

[21] S. A. Parsons, C. Amy, A. C. Hutchison et al., "U.S. teachers' perceptions of online professional development," Teaching and Teacher Education, vol. 82, pp. 33-42, 2019.

[22] A. Simpson, M. Walsh, and J. Rowsell, "The digital reading path: researching modes and multi-directionality with iPads," Literacy, vol. 47, no. 3, pp. 123-130, 2013.

[23] J. S. Eccles, T. F. Adler, R. Futterman, S. B. Goff, C. M. Kaczala, and J. L. Meece, "Expectancies, values, and academic behaviors," in Achievement and Achievement Motivation, J. T. Spence, Ed., pp. 75-146, W. H. Freeman, San Francisco, CA, USA, 1983.

[24] N. L. Davis, M. Gough, and L. L. Taylor, "Online teaching: advantages, obstacles and tools for getting it right," Journal of Teaching in Travel \& Tourism, vol. 19, pp. 1-8, 2019.

[25] G. W. Hislop and H. J. C. Ellis, "A study of faculty effort in online teaching," The Internet and Higher Education, vol. 7, no. 1, pp. 15-32, 2004.

[26] J. K. Smedley, "Modelling the impact of knowledge management using technology," Insight, vol. 23, pp. 233-250, 2010.

[27] A. M. Limperos, M. M. Buckner, R. Kaufmann, and B. N. Frisby, "Online teaching and technological affordances: an experimental investigation into the impact of modality and clarity on perceived and actual learning," Computers \& Education, vol. 83, pp. 1-9, 2015.

[28] A. F. Algahtani, "Evaluating the effectiveness of the e-learning experience in some universities," in Saudi Arabia from Male Students' Perceptions Durham University, Durham, UK, 2011.

[29] K. S. Betts, "An institutional overview: factors influencing faculty participation in distance education in postsecondary education in the United States: an institutional study," Online Journal of Distance Learning Administration, vol. 1, no. 3, pp. 1-15, 1998, http://www.westga.edu/ distance/Betts13. html.

[30] S. Panda and S. Mishra, "E-learning in a mega open university: faculty attitude, barriers and motivators," Educational Media International, vol. 44, no. 4, pp. 323-338, 2007.

[31] I. E. Allen and J. Seaman, Online Nation: Five Years of Growth in Online Learning, Sloan-C, Needham, MA, USA, 2007, http://www.sloan-c.org/publications/survey/pdf/online_nation. pdf.

[32] T. Bender, Discussion-Based Online Teaching to Enhance Student Learning, Stylus, Sterling, VA, USA, 2003.
[33] S. Santilli and V. Beck, "Graduate faculty perceptions of online teaching," Quarterly Review of Distance Education, vol. 6, no. 2, pp. 155-160, 2005.

[34] R. Sellani and W. Harrington, "Addressing administrator/ faculty conflict in an academic online environment," The Internet and Higher Education, vol. 5, no. 2, pp. 131-145, 2002.

[35] J. Arbaugh, "Sage, guide, both, or even more? An examination of instructor activity in online MBA courses," Computers \& Education, vol. 55, no. 3, pp. 1234-1244, 2010.

[36] M. L. Hung and C. Chou, "Students' perceptions of instructors' roles in blended and online learning environments: a comparative study," Computers \& Education, vol. 81, pp. 315-325, 2015.

[37] J. Schoonenboom, "The use of technology as one of the possible means of performing instructor tasks: putting technology acceptance in context," Computers \& Education, vol. 59, no. 4, pp. 1309-1316, 2012.

[38] I. B. Ohanu and C. H. Chukwuone, "Constraints to the use of online platform for teaching and learning technical education in developing countries," Education and Information Technologies, vol. 23, no. 6, pp. 3029-3045, 2018.

[39] A. Ebrahimi, E. Faghih, and S. S. Marandi, "Factors affecting pre-service teachers' participation in asynchronous discussion: the case of Iran," Australasian Journal of Educational Technology, vol. 32, no. 2, pp. 115-129, 2016.

[40] H. Lee, H. Chang, and L. Bryan, "Doctoral students' learning success in online-based leadership programs: intersection with technological and relational factors," International Review of Research in Open and Distance Learning, vol. 21, no. 1, pp. 61-81, 2020.

[41] M. Abushammala, W. Qazi, and R. K. Manchiryal, "The impact of COVID-19 on the private higher education system and students in Oman," Journal of University Teaching and Learning Practice, vol. 18, no. 3, p. 13, 2021.

[42] M. M. Ghashghagh, V. Mahdi Nezhad, and N. M. Yaghoobi, "Assessing factors affecting the tendency to use electronic learning systems among faculty members," Magazine of E-Learning Distribution in Academy, vol. 2, no. 3, pp. 28-38, 2011, http://mediaj.ir/online/browse.php?a_code=A-10-637\&slc_lang=en\&sid=1.

[43] B. E. Zamani, A. Esfijani, and S. M. Abdellahi Damaneh, "Major barriers for participating in online teaching in developing countries from Iranian faculty members' perspectives," Australian Journal of Educational Technology, vol. 32, no. 3, pp. 38-49, 2016.

[44] R. Gopal, V. Singh, and A. Aggarwal, "Impact of online classes on the satisfaction and performance of students during the pandemic period of COVID 19," Education and Information Technologies, pp. 1-25, Springer, Cham, Switzerland, 2021.

[45] A. Alghamdi, "COVID-19 mandated self-directed distance learning: experiences of Saudi female postgraduate students," Journal of University Teaching and Learning Practice, vol. 18, no. 3, p. 14, 2021.

[46] T. T. T. Pham, H. A. Le, and D. T. Do, "The factors affecting students' online learning outcomes during the COVID-19 pandemic: a Bayesian exploratory factor Analysis," Educational Research International, vol. 2021, Article ID 2669098, 13 pages, 2021.

[47] J. T. Richardson, "The concepts and methods of phenomenographic research," Review of Educational Research, vol. 69, no. 1, pp. 53-82, 1999.

[48] F. G. Murillo and N. Hidalgo, "Students' conceptions about a fair assessment of their learning," Studies in Educational Evaluation, vol. 53, pp. 10-16, 2017. 
[49] M. Miles and A. M. Huberman, Qualitative Data Analysis: An Expanded Sourcebook, Sage, Thousand Oaks, CA, USA, 2nd edition, 1994.

[50] B. G. Glaser, Theoretical Sensitivity: Advances in the Methodology of Grounded Theory, Sociology Press, Mill Valley, CA, USA, 1978.

[51] F. Marton, "Phenomenography: a research approach to investigating different understandings of reality," Journal of Thought, vol. 21, no. 3, pp. 28-49, 1986.

[52] B. Sjöström and L. O. Dahlgren, "Applying phenomenography in nursing research," Journal of Advanced Nursing, vol. 40, no. 3, pp. 339-345, 2002.

[53] L. R. Harris, "A phenomenographic investigation of teacher conceptions of student engagement in learning," Australian Educational Researcher, vol. 35, no. 1, pp. 57-79, 2008.

[54] C. Hemsley, "Jones International University's focus on quality e-learning opens doors for students worldwide," Business Media, vol. 39, no. 9, pp. 26-29, 2002.

[55] C. Yot-Domínguez and C. Marcelo, "University students' selfregulated learning using digital technologies," International Journal of Educational Technology in Higher Education, vol. 14, pp. 1-18, 2017.

[56] P. Ice, R. Curtis, P. Phillips, and J. Wells, "Using asynchronous audio feedback to enhance teaching presence and students' sense of community," Journal of Asynchronous Learning Networks, vol. 11, no. 2, pp. 1-23, 2007, http://olc. onlinelearningconsortium.org/jaln/v11n2/.

[57] I. Luyt, "Bridging spaces: cross-cultural perspectives on promoting positive online learning experiences," Journal of Educational Technology Systems, vol. 42, no. 1, pp. 3-20, 2013.

[58] J. Hartman, C. Dziuban, and P. Moskal, "Faculty satisfaction in ALNs: a dependent or independent variable?" Journal of Asynchronous Learning Networks, vol. 4, no. 3, pp. 155-179, 2000, http://www.sloan-c.org/publications/jaln/v4n3/pdf/ v4n3_hartman.pdf.

[59] M. Thompson, Practice: Analysis of Faculty Experience and Initial Identification of Standards of Excellence, Needham, MA, USA, 2002, http://www.sloanc.org/effective/details4.asp? FS_ID $=29$.

[60] D. Mohammadi, S. Hosseıni, and H. Fami, "Investigating agricultural instructors' attitudes toward e-learning in Iran," The Turkish Online Journal of Distance Education, vol. 12, no. 1, pp. 174-183, 2011.

[61] S. K. Rockwell, J. Schauer, S. M. Fritz, and D. B. Marx, "Incentives and obstacles influencing higher education faculty and administrators to teach via distance," Online Journal of Distance Learning Administration, vol. 2, no. 4, pp. 18-38, 1999.

[62] J. Yu and Y. Jee, "Analysis of online classes in physical education during the COVID-19 pandemic," Education Sciences, vol. 11, no. 1, p. 3, 2021.

[63] B. S. Sedghpour and S. Mirzaee, "Attitudinal challenges of the members of faculty in electronic education," Technology and Education Journal, vol. 3, no. 1, pp. 77-87, 2009, [In Persian].

[64] A. Kamble, R. Gauba, S. Desai, and D. Golhar, "Learners' perception of the transition to instructor-led online learning environments: Facilitators and barriers during the COVID-19 pandemic," International Review of Research in Open and Distributed Learning, vol. 22, no. 1, pp. 199-215, 2021.

[65] D. Jaramillo-Morillo, J. Ruipérez-Valiente, M. F. Sarasty, and G. Ramírez-Gonzalez, "Identifying and characterizing students suspected of academic dishonesty in SPOCs for credit through learning analytics," International Journal of Educational Technology in Higher Education, vol. 17, pp. 1-18, 2020.
[66] W. F. Wade and B. G. Peggy, "Perceptions of online instruction among university faculty," TOJET: The Turkish Online Journal of Educational Technology, vol. 8, no. 1, 2009.

[67] C. J. Bonk, The Perfect E-Storm: Emerging Technologies, Enhanced Pedagogy, Enormous Learner Demand, and Erased Budgets, The Observatory on Borderless Higher Education, London, UK, 2004. 